\title{
Urinary Ammonium Excretion in Primary Gout*
}

\author{
Alexander B. Gutman † and Ts'aI-fan Yü \\ (From the Department of Medicine, The Mount Sinai Hospital, New York, N. Y.)
}

The present investigation of the urinary ammonium excretion in gouty subjects stems from prior isotope studies suggesting an abnormality of glutamine metabolism in primary gout $(1,2)$, apparently involving the utilization of glutamine for ammonia production by the kidneys and for $d e$ novo synthesis of uric acid by the liver. A résumé of the previous findings will explain the relevance of the present studies.

When equivalent doses of $\mathrm{N}^{15}$-glycine were given to gouty and nongouty subjects, and the intramolecular distribution of the urinary $\mathrm{N}^{15}$-uric acid was then compared, it was found in the gouty that uric acid N-9 and N-3, both derived from glutamine amide nitrogen, were disproportionately enriched initially $(1,2)$. Of several possible interpretations of this abnormality, one is that heavily labeled glutamine amide nitrogen, derived from $\mathrm{N}^{15}$-glycine, had been diverted from an alternative pathway of glutamine utilization to de novo purine biosynthesis, and this enriched glutamine admixture in the liver then yielded a greater $\mathrm{N}^{15}$ abundance at uric acid N-9 and N-3. Among such alternative pathways of glutamine utilization is that leading to production of ammonia by the kidneys (3), a pathway particularly relevant because there is normally a prompt (but brief) outpouring of very richly labeled $\mathrm{N}^{15}$-ammonium in the urine after administration of $\mathrm{N}^{15}$-labeled glycine or aspartic acid $(4,5)$. That heavily labeled glutamine nitrogen ordinarily destined for elimination as $\mathrm{N}^{15}$-ammonium might indeed be the source of the disproportionate enrichment of uric acid N-9 and $\mathrm{N}-3$ in gout was suggested by the finding that in gouty subjects apparently free of renal disease and

\footnotetext{
* Submitted for publication February 16, 1965 ; accepted May 17, 1965.

This work was supported in part by a grant-in-aid (A-162) from the National Institute of Arthritis and Metabolic Diseases.

$\dagger$ Address requests for reprints to. Dr. Alexander B. Gutman, Dept. of Medicine, The Mount Sinai Hospital, 100th St. and Fifth Ave., New York, N. Y. 10029.
}

excreting comparably acid urine, the per cent $\mathrm{N}^{15}$ dose initially eliminated as $\mathrm{N}^{15}$-ammonium was appreciably diminished. In gouty overexcretors of uric acid, the urinary excretion of $\mathrm{N}^{15}$-ammonium was decreased to about half of the normal; in gouty normoexcretors of uric acid it was diminished about one-third. This discrepancy was not due to any decline in the high specific activity of such ammonium as was excreted (thus minimizing the possibility of some gross abnormality in the reactions or pools involved in the transfer of $\mathrm{N}^{15}$ to glutamine) but to a decrease in the quantity of ammonium appearing in the urine. This would suggest either that less glutamine was delivered to or extracted by the kidneys, or both, despite the acidity of the urine, or that glutamine was not properly utilized by the kidney for ammonia formation, the surplus glutamine being recycled and made available to the liver for conversion to urea and uric acid.

These isotope studies were limited to six gouty and four nongouty subjects, and indicated the desirability of the present investigation, which deals with the renal excretion of (unlabeled) ammonium, after an overnight fast, and also under conditions of mild acidosis induced with ammonium chloride, in a larger segment of the gouty population free of overt renal disease. From the outset it was apparent that there were large variations in the urinary ammonium excretion within both normal and gouty groups of subjects, even at the same (acid) urine $\mathrm{pH}$, and that there was much overlap between the two groups. Nevertheless, when the mean values of a sufficiently large number of gouty and nongouty subjects were compared, differences of statistical significance were found that seem to conform to the isotope studies in implying some deficiency in the renal production of ammonia in primary gout.

\section{Methods}

For studies under the conditions of a normal metabolic acid load, in the postabsorptive state, 46 normouricemic 
nongouty men, ages 24 to 62 years (mean, 35), served as control subjects for 97 men with primary gout, age 21 to 60 years (mean, 48). The normal control subjects were selected as appropriate for study only if they excreted urine of $\mathrm{pH}$ less than 6.0 after an overnight fast, in order that they could be more closely paired with the gouty subjects, most of whom excreted distinctly acid urine under the same conditions. The serum nonprotein nitrogen in all cases, gouty and nongouty, was not in excess of $40 \mathrm{mg}$ per $100 \mathrm{ml}$; the serum creatinine was less than $1.6 \mathrm{mg}$ per $100 \mathrm{ml}$. All gouty subjects with creatinine or inulin clearances less than $80 \mathrm{ml}$ per minute were excluded from the study.

The urinary excretion of uric acid in 40 gouty subjects was habitually in excess of the normal on an equivalent purine and protein intake (gouty overexcretors of uric acid), and in the remainder was within normal limits (gouty normoexcretors). Forty-one of the patients with gout gave a history of renal calculi, but those with manifest urinary infection or overt pyelonephritis were disqualified. The use of uricosuric agents was discontinued before the study in all gouty subjects taking them.

Urine collections were made in the morning, after discarding the first (overnight) voiding. The subjects were in the postabsorptive state, without breakfast except for one or two glasses of water to ensure adequate diu- resis (mean urine flow, $1.2 \mathrm{ml}$ per minute). Two- or three-hour urine samples were obtained, and measurements were made, without delay, of $\mathrm{pH}$, ammonia, titratable acid, uric acid, and creatinine, the last to aid in detecting collection errors in bladder emptying, etc. A blood specimen also was procured.

For the ammonium chloride loading test, the procedure of Wrong and Davies (6) was first attempted, but was so plagued not only by gastrointestinal upsets but also by prompt precipitation of acute gouty attacks that it had to be abandoned. Finally adopted was a dosage of ammonium chloride in syrup, $2.0 \mathrm{~g}$ four times a day for day 1 , followed by $1.0 \mathrm{~g}$ four times a day for 3 consecutive days, an acidifying regimen that proved to be sufficient for our purpose, rapidly reducing the urine $\mathrm{pH}$ almost invariably below 5.0 (mean, 4.8 ). This procedure could be carried through satisfactorily in 24 subjects. Six of these were nongouty normouricemic controls (ages 32 to 51 years; mean, 38), 14 were hyperuricemic and gouty (ages 18 to 58 years; mean, 40 ), and 4 (ages 23 to 49 years; mean, 41) were hyperuricemic uric acid stone formers (serum uric acid 7.1 to $8.2 \mathrm{mg}$ per $100 \mathrm{ml}$; mean, $7.6 \mathrm{mg}$ per $100 \mathrm{ml}$ ) and considered to be gouty although they had not experienced typical acute attacks. The last four cases mentioned were classified as presumptively gouty because in gout uric acid urolithiasis may antedate

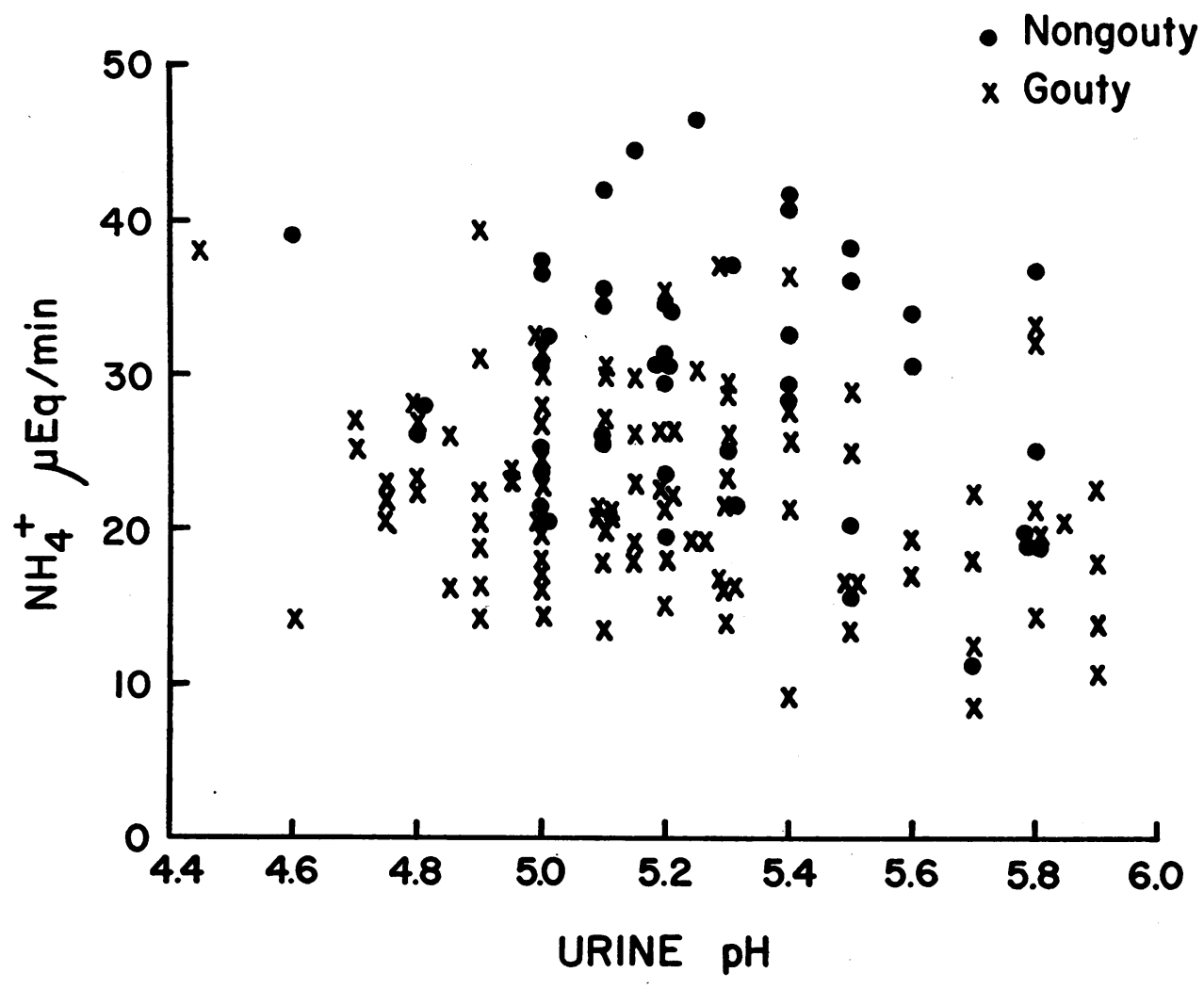

Fíg. 1. Úrinary excretion of ammonium, in relation to urine pH, in 46 nongouṭy AND 97 GOUTY SUBJECTS, 


\section{- Nongouty \\ $x$ Gouty}

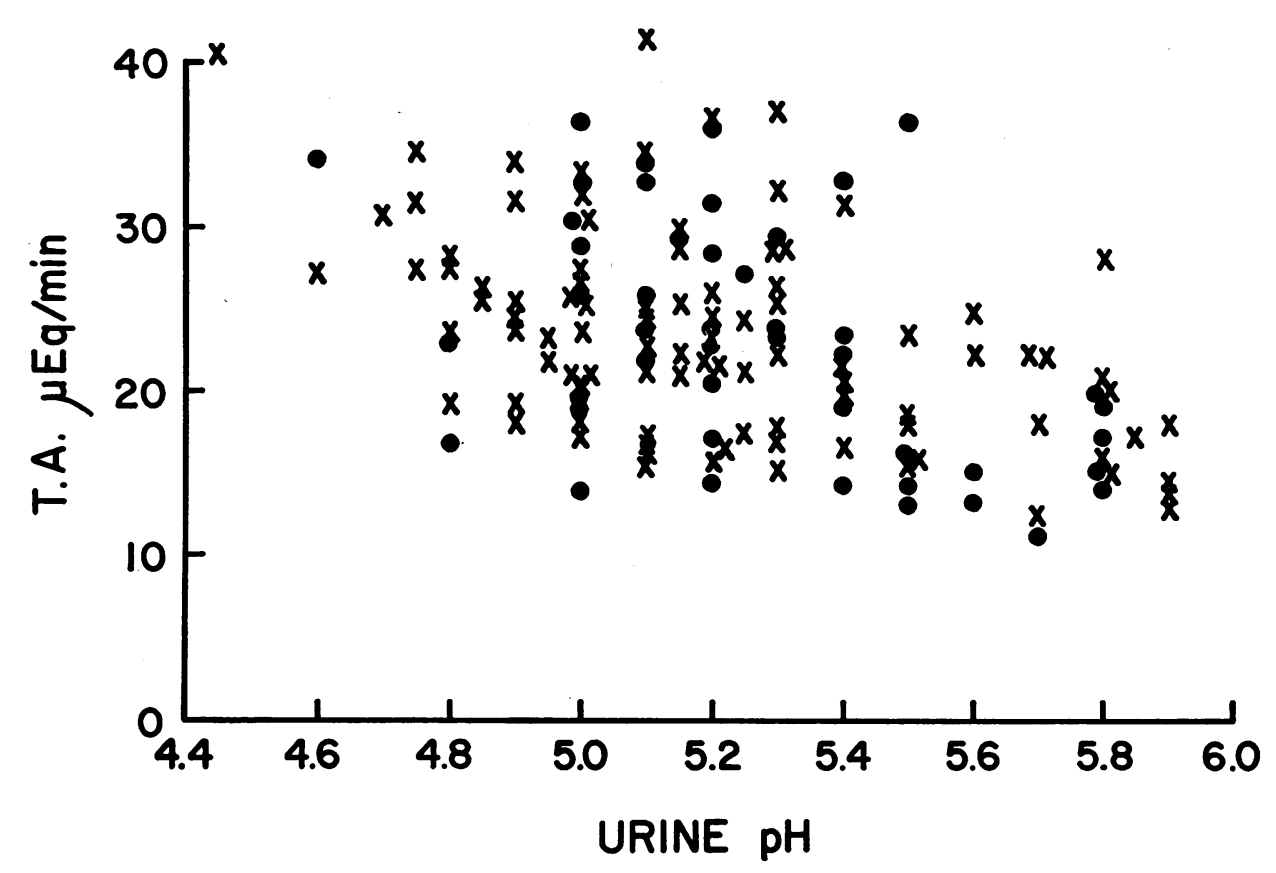

Fig. 2. Urinary exCREtion of titratable acid (T.A.), IN RElation to URINe PH, in 46 NONGOUTY AND 97 GOUTY SUBJECTS.

the initial attack of acute arthritis, as occurred in $30 \%$ of our 265 overtly gouty subjects who had developed stone.

After obtaining two or three control 24-hour urine samples, daily collections were made during the period of ammonium chloride administration and for 2 or 3 days thereafter. All 24-hour voidings were collected under paraffin oil and preserved with toluene. Soon after completion of each day's collection, measurements of $\mathrm{pH}$, ammonia, titratable acid, creatinine, uric acid, and total nitrogen were made. Fasting venous blood samples for determination of bicarbonate were procured under paraffin oil, using heparin as anticoagulant, on the morning preceding the first dose of ammonium chloride and on the morning after the last evening dose. The dietary protein intake was checked by the urinary total nitrogen excretion, and the means were found to be comparable in the gouty and nongouty groups before and after administration of ammonium chloride.

Since under these conditions of acid loading the maximal urinary ammonium levels achieved were reached by day 3 , the data recorded here represent the means of days 3 and 4 . The completeness of daily urine collections was checked by creatinine determinations. The average daily output of creatinine in the premedication control period was $1.78 \mathrm{~g}$ per day in the nongouty subjects and $1.92 \mathrm{~g}$ per day in the gouty; after administration of am- monium chloride it averaged $1.73 \mathrm{~g}$ per day in the nongouty and $1.88 \mathrm{~g}$ per day in the gouty.

Standard analytical methods were employed: urine $\mathrm{pH}$ by Beckman $\mathrm{pH}$ meter (without correction to body temperature); ammonia by the method of Van Slyke and Cullen (7); titratable acidity by titration with $0.1 \mathrm{~N}$ $\mathrm{NaOH}$ to $\mathrm{pH} 7.4$ ( $\mathrm{pH}$ meter) ; creatinine by the method of Bonsnes and Taussky (8) ; uric acid spectrophotometrically, with the use of purified uricase (9); total nitrogen by the micro-Kjeldahl method.

\section{Results}

Urine $p H$ in primary gout. It is pertinent first to observe, since it has been virtually unnoticed and unexplained, that excretion of distinctly acid urine is far more prevalent among patients with primary gout than among the nongouty. The $\mathrm{pH}$ of urine samples voided in the morning before breakfast, after an approximately 12-hour overnight fast, was in the range $<4.8$ to 5.0 in no less than a third of 223 gouty subjects, was less than 5.4 in about $70 \%$, and was 6.0 or more in only $4 \%$. In some cases in which observations were 
TABLE I

Excretion of ammonium, titratable acid (T.A.), and uric acid in morning urine samples of 97 gouty and 46 nongouty subjects (means and standard deviations)

\begin{tabular}{|c|c|c|c|c|c|c|c|c|}
\hline Urine $\mathrm{pH}$ & Subjects & $\mathrm{NH}_{4}{ }^{+}$ & T.A. & $\begin{array}{l}\mathrm{NH}_{4}^{+} \\
+ \text {T.A. }\end{array}$ & $\frac{\mathrm{NH}_{4}^{+}}{\mathrm{NH}_{4}{ }^{+}+\text {T.A. }}$ & Uric acid & $\frac{\mathrm{NH}_{4}+-\mathrm{N}}{\text { Uric acid-N }}$ & Creatinine \\
\hline & & $\mu E q / \min$ & $\mu E q / \min$ & $\mu E q / \min$ & $\%$ & $m g / \min$ & $\%$ & $m g / m i n$ \\
\hline \multirow[t]{2}{*}{$<4.8-5.0$} & Nongouty (11) & $31.2 \pm 4.9$ & $25.8 \pm 4.0$ & 57.0 & 55.5 & $0.42 \pm 0.11$ & 3.35 & $1.20 \pm 0.19$ \\
\hline & Gouty & $23.7 \pm 6.2$ & $26.9 \pm 6.4$ & 50.7 & 46.7 & $0.52 \pm 0.14$ & 2.04 & $1.25 \pm 0.18$ \\
\hline \multirow[t]{2}{*}{$5.1-5.3$} & Nongouty (18) & $32.0 \pm 7.4$ & $26.1 \pm 5.5$ & 58.1 & 54.9 & $0.46 \pm 0.12$ & 3.08 & $1.24 \pm 0.20$ \\
\hline & Gouty & $23.1 \pm 5.9$ & $24.0 \pm 6.5$ & 47.1 & 49.2 & $0.54 \pm 0.15$ & 1.98 & $1.22 \pm 0.20$ \\
\hline \multirow{2}{*}{$5.4-5.6$} & Nongouty (11) & $31.8 \pm 7.7$ & $18.9 \pm 6.6$ & 50.7 & 62.8 & $0.48 \pm 0.13$ & 2.90 & $1.26 \pm 0.16$ \\
\hline & Gouty (13) & $21.6 \pm 7.1$ & $21.4 \pm 4.7$ & 43.0 & 49.3 & $0.58 \pm 0.13$ & 1.58 & $1.21 \pm 0.13$ \\
\hline \multirow{2}{*}{$5.7-5.9$} & Nongouty $(6)$ & $22.0 \pm 4.9$ & $16.3 \pm 3.0$ & 38.3 & 56.2 & $0.42 \pm 0.09$ & 2.33 & $1.20 \pm 0.19$ \\
\hline & Gouty & $19.3 \pm 7.7$ & $18.1 \pm 4.3$ & 37.4 & 49.8 & $0.55 \pm 0.12$ & 1.58 & $1.26 \pm 0.21$ \\
\hline
\end{tabular}

continued throughout the day, the distinct acidity of the urine was found to persist, with only minor diurnal fluctuations.

Urinary excretion of metabolic acid with normal acid loads. Figures 1 and 2 show the distribution of points representing the results of determinations of ammonium and titratable acid, in relation to urine $\mathrm{pH}$ less than 6.0 , in the morning urine samples of 46 nongouty and 97 gouty subjects who appeared to be free of overt renal damage as judged by the criteria mentioned under Methods. As in similar studies by others, there was considerable dispersion of the results in the normal control group, due to a multiplicity of variables, some uncontrolled or uncontrollable. A like dispersion is shown by the gouty subjects, with much overlap between the two groups. Nevertheless, in Figure 1 no less than $88 \%$ of the points representing urinary excretion of ammonium in the gouty fall below the normal mean ammonium elimination at corresponding levels of acid urine $\mathrm{pH}$, whereas in Figure 2 the points representing urinary excretion of titratable acid in the gouty are about equally distributed above and below the corresponding normal means.
These differences are brought out more clearly in Table I, in which the relevant means and standard deviations are given in ascending order of urine $\mathrm{pH}$, at intervals of $0.3 \mathrm{pH}$ unit. In each category of gouty subjects except those with urine $\mathrm{pH}>5.7$, the mean urinary ammonium was found to be significantly less than in the nongouty ( $p<$ 0.01 in all but the last group), whereas there was no significant difference in respect to excretion of titratable acid. The mean urinary ammonium deficit in the gouty subjects, as compared to the nongouty, varied from 7.5 to $10.2 \mu \mathrm{Eq}$ per minute in the several urine $\mathrm{pH}$ categories below $\mathrm{pH}$ 5.7. The ratio, ammonium/ammonium plus titratable acid, thus tended to be lower in such gouty subjects, who also appeared to have a net deficit in urinary excretion of metabolic acid (ammonium plus titratable acid, since bicarbonate need not be considered here). This apparent deficit in metabolic acid excretion averaged approximately $8 \mu \mathrm{Eq}$ per minute in the gouty who excreted urine in the $\mathrm{pH}$ range below 5.7, a significant difference from the normal $(p<0.01)$. Table $I$ also indicates that the mean urinary uric acid excretion was somewhat increased in the gouty subjects, and the

TABLE II

Twenty-four hour urinary excretion of ammonium, titratable acid, and uric acid before and after ammonium chloride administration to 18 gouty and 6 nongouty subjects (means and standard deviations)

\begin{tabular}{|c|c|c|c|c|c|c|c|c|c|}
\hline & Subjects & Plasma $\mathrm{HCO}_{3}^{-}$ & $\underset{\text { pH }}{\text { Urine }}$ & $\mathrm{NH}_{4}^{+}$ & T.A. & $\begin{array}{l}\mathrm{NH}_{4}{ }^{+} \\
+ \text {T.A. I }\end{array}$ & $\frac{\mathrm{NH}_{4}{ }^{+}}{\mathrm{NH}_{4}{ }^{+}+\mathrm{T} \cdot \mathrm{A} .}$ & $\begin{array}{l}\text { Uric } \\
\text { acid }\end{array}$ & $\frac{\mathrm{NH}_{4}+-\mathrm{N}}{\text { Uric acid-N }}$ \\
\hline & & $m E q / L$ & & $m E q / d a y$ & $m E q / d a y$ & $m E q / d a y$ & $\%$ & $m g / d a y$ & $\%$ \\
\hline \multirow{2}{*}{$\begin{array}{l}\text { Before } \\
\mathrm{NH}_{4} \mathrm{Cl}\end{array}$} & Nongouty (6) & $26.0-29.0(27.0)$ & 5.5 & $43.0 \pm 7.5$ & $33.7 \pm 7.4$ & 76.7 & 56.3 & 739 & 2.4 \\
\hline & Gouty & $24.5-31.0(27.0)$ & 5.3 & $37.5 \pm 10.1$ & $41.4 \pm 11.7$ & 78.9 & 47.4 & 823 & 1.9 \\
\hline \multirow{2}{*}{$\begin{array}{l}\text { After } \\
\mathrm{NH}_{4} \mathrm{Cl}\end{array}$} & Nongouty (6) & $21.0-24.5(23.0)$ & 4.8 & $79.4 \pm 12.6$ & $51.2 \pm 5.2$ & 130.6 & 60.5 & 700 & 4.8 \\
\hline & Gouty & $20.0-26.0(23.0)$ & 4.8 & $62.6 \pm 11.5$ & $52.2 \pm 9.7$ & 114.4 & 54.4 & 783 & 3.3 \\
\hline
\end{tabular}


urinary anmonium nitrogen/uric acid nitrogen ratios correspondingly were lower than normal. The urinary excretion of creatinine did not differ appreciably in the gouty and nongouty groups.

In Table II (control data) the 24-hour urinary elimination of ammonium and titratable acid in 18 patients with primary gout is compared with that of 6 normouricemic nongouty subjects. Before administration of ammonium chloride, the range of urine $\mathrm{pH}$ was 4.9 to 5.9 (mean, 5.3) in the gouty, and 5.3 to 6.2 (mean, 5.5) in the nongouty. Despite appreciable overlap in the two groups, there was a trend to lower urinary ammonium and higher titratable acid excretion in the gouty. The mean urinary excretion of ammonium and titratable acid in the gouty was 37.5 and $41.4 \mathrm{mEq}$ per day, respectively, as compared to respective means of 43.0 and $33.7 \mathrm{mEq}$ per day in the nongouty. The number of observations is small, however, and the differences are not statistically significant. The mean ammonium/ammonium plus titratable acid ratio was $47.4 \%$ in the gouty and $56.3 \%$ in the nongouty $(p<0.01)$. The mean ratio, ammonium nitrogen/total nitrogen, was $3.7 \%$ in the gouty and $4.6 \%$ in the nongouty. But in contrast to the findings in the morning urine samples, collected after an overnight fast, there was an increase in titratable acid excretion in the 24-hour urine collections in the gouty, sufficient to compensate for their deficiency in ammonium, and the total metabolic acid excretion in the two groups was about the same, with means of 78.9 and $76.7 \mathrm{mEq}$ per day.

Included in Table II are four hyperuricemic subjects so prone to stone that they had developed uric acid urolithiasis but not acute gouty arthritis; as noted under Methods these cases are considered nevertheless to be gouty. Their urine $\mathrm{pH}$ was 5.2 to 5.3 , their urinary ammonium excretion was low (mean, $33.9 \pm 5.3 \mathrm{mEq}$ per day), and their mean daily excretion of titratable acid was $39.0 \pm$ $7.9 \mathrm{mEq}$ per day.

Urinary excretion of metabolic acid after administration of ammonium chloride. As shown in Table II, under the stress of a moderately increased metabolic acid load the urinary excretion of ammonium and titratable acid was enhanced in the gouty as well as in the nongouty, although the response was somewhat less pronounced in the former, In the 6 nongouty control subjects, the urinary elimination of ammonium rose from a mean of 43.0 to $79.4 \mathrm{mEq}$ per day, a mean increment of $36.4 \mathrm{mEq}$ per day; in the 18 gouty subjects, the urinary elimination of ammonium increased from a mean of 37.5 to $62.2 \mathrm{mEq}$ per day, for a mean rise of $24.7 \mathrm{mEq}$ per day. This difference in increments of urinary ammonium in the two groups is of borderline significance $(0.02<p$ $<0.05)$. Excretion of titratable acid increased from a mean of 33.7 to $51.2 \mathrm{mEq}$ per day, a mean increment of $17.5 \mathrm{mEq}$ per day, in the nongouty, as compared to an increase from a mean of 41.4 to $52.2 \mathrm{mEq}$ per day; a mean increment of $10.8 \mathrm{mEq}$ per day, in the gouty. This difference is of significance $(0.01<\mathrm{p}<0.02)$.

Thus the deficit in urinary ammonium excretion in the gouty before ammonium chloride was administered, initially averaging $5.5 \mathrm{mEq}$ per day, increased to $17.2 \mathrm{mEq}$ per day under the stress of an augmented metabolic acid load $(p=0.01)$. The urinary excretion of titratable acid in the gouty exceeded that in the nongouty before administration of ammonium chloride, by a mean of $7.7 \mathrm{mEq}$ per day, but after acidosis was induced the titratable acid eliminated in the gouty and nongouty was about the same, 52.2 and $51.2 \mathrm{mEq}$ per day, respectively. Consequently, after administration of ammonium chloride the gouty subjects were left with a mean net deficit of $16.2 \mathrm{mEq}$ per day in the urinary excretion of metabolic acid, as compared to the normal mean $(p<0.01)$. It was expected that this retention of hydrogen ions would be reflected in a demonstrably lower plasma bicarbonate concentration, but the available figures (Table II) do not show this, apparently because the differences were too minor for detection in blood samples procured 12 hours after the last dose of ammonium chloride had been taken.

In both gouty and nongouty there was some reduction in the renal output of uric acid when ammonium chloride was administered, not proportionate to the rise in urinary ammonium excretion. Hence the ratios, ammonium nitrogen/uric acid nitrogen, rose in both groups, but in the nongouty remained higher than in the gouty.

\section{Discussion}

The present study indicates that the urine $\mathrm{pH}$ in patients with primary gout tends to be distinctly 
more acid than in most normal human subjects. This circumstance doubtless contributes to the striking predisposition of the gouty to uric acid urolithiasis, which characteristically occurs in acid urine. In gouty normoexcretors of uric acid, who constitute about 70 to $75 \%$ of the gouty population, the incidence of uric acid stone formation is 10 to $20 \%$ (10), more than a thousandfold higher than in the population at large, in which it is estimated to be somè $0.01 \%(11)$. In gouty overexcretors of uric acid, the excess of uric acid in the urine further increases the incidence of uric acid stone to about $40 \%$ (10).

The data also indicate that when the urine $\mathrm{pH}$ is less than 5.7 in the gouty, as it usually is, the renal elimination of ammonia in relation to urine $\mathrm{pH}$ is apt to be somewhat deficient. It is implied that this deficiency contributes to the unduly low urine $\mathrm{pH}$, since the $\mathrm{pH}$ of the urine tends to rise as the anmonia produced by the kidneys diffuses into the tubular lumen and reacts there with hydrogen ions (12). The deficit in hydrogen ion excretion implicit in the deficiency of urinary ammonium ordinarily is more or less compensated for by an equivalent increase in titratable acid; hence there is no perceptible systemic acidosis. However, preservation of acid-base balance seems to be somewhat more precarious in gouty than in normal man, and after an approximately 12 -hour overnight fast a mean deficit in urinary elimination of metabolic acid (ammonium plus titratable acid) of approximately $8 \mu \mathrm{Eq}$ per minute was found. After administration of an acidifying salt (ammonium chloride) the urinary excretion of ammonium increased appreciably, but less than in the nongouty control subjects, and the deficit in urinary elimination of metabolic acid under these circumstances rose to a mean of approximately $16 \mathrm{mEq}$ per day.

These figures raise the question whether the implied deficiency in urinary elimination of ammonium is due to an inherent defect in renal production of ammonia in primary gout or simply to secondary renal injury superimposed by urate deposits in the kidney, pyelonephritis, aging, etc. It has long been known that the urinary excretion of ammonium is substantially reduced in patients with advanced kidney disease, such as chronic glomerulonephritis with uremia $(13,14)$, despite elimination of distinctly acid urine, although even in such circumstances renal production of ammonia may be surprisingly well preserved (15). A significant reduction in urinary ammonium excretion has been reported to occur in association with aging (16). Relatively minor injury due to pyelonephritis, it is said, may cause an appreciable decrease in renal production of ammonia, but when this impression was recently tested by Steinmetz, Eisinger, and Lowenstein (17), they could detect no specific tubular defect in ammonia production in such cases unless the functioning nephron mass was substantially reduced, as reflected in an unequivocally lower glomerular filtration rate. In 1960, in a review of the pertinent literature, McCance, Matheson, Gresham, and Elkinton (18) were hard put to find a single recorded case of selective impairment of ammonia formation by the kidneys, in which other indications of overt renal damage were lacking. [In renal tubular acidosis and allied disorders, the urinary elimination of ammonium is meager, but this is associated with a relatively high urine $\mathrm{pH}$, not with a markedly reduced renal capacity to produce ammonia (19).] More recently, Henneman, Wallach, and Dempsey (20) described a specific renal defect in excretion of ammonium associated with uric acid stone formation in nongouty subjects, an observation confirmed in some such cases (21) but not in others (16).

Of course, the kidneys may be severely injured in gout, from a variety of causes, but the gouty subjects accepted for the present study did not have perceptible kidney damage, as judged by the criteria for selection of cases indicated under Methods; and in general, even in older persons with manifest gout of long standing, the glomerular filtration rate and effective renal plasma flow, and other indexes of renal function, are usually remarkably well preserved in relation to age (22). To be sure, in primary gout there is said to be a specific defect in renal tubular transfer of uric acid, to which is ascribed the hyperuricemia characteristic of the disorder, but for reasons set forth elsewhere $(23,24)$ we do not find the evidence for this compelling. In the present series of cases aging did not appear to be a significant factor in the modest reduction in urinary elimination of ammonium found, since of the 83 gouty subjects with urine $\mathrm{pH}<4.8$ to 5.6 included in Table $\mathrm{I}$, the mean urinary ammonium excretion of the 19 who were in the age range 21 to 40 was 
$23.9 \mu \mathrm{Eq}$ per minute; of 28 in the age range 41 to 50 it was $23.1 \mu \mathrm{Eq}$ per minute; and of 36 in the age range 51 to 60 it was $22.7 \mu \mathrm{Eq}$ per minute. The diet in relation to protein and other items was not rigidly controlled on a metabolic ward, but the equivalence of urine $\mathrm{pH}$ and total nitrogen excretion already noted would indicate that differences in diet were not chiefly responsible for the mean differences in urinary elimination of ammonium observed in the gouty and nongouty. Consideration was given to the effects of marked sodium and potassium depletion on the renal production of ammonia (25), and we excluded from the study gouty subjects who also had hypertension or cardiac disease, or both, and were taking diuretics that may induce such depletion. Insidious and elusive renal injury from urate deposits in the kidney and "pyelonephritis" may occur in gouty subjects, notably those with recurrent uric acid urolithiasis, who are well represented in this series of patients with distinctly acid urine, but the mean urinary elimination of ammonium by the 50 noncalculous gouty subjects excreting urine with $\mathrm{pH}$ $<4.8$ to 5.6 (Table I) was $25.3 \pm 6.3 \mu \mathrm{Eq}$ per minute, a figure significantly lower than that of the nongouty control subjects $(p=0.01)$. It is therefore concluded that while secondary renal damage cannot be wholly excluded in the present series of cases of primary gout, and doubtless plays a contributory role of varying importance in the gouty population at large, this does not sufficiently account for the selective impairment in the renal production of ammonia, in relation to excretion of distinctly acid urine, here described.

It has been suggested $(1,2)$ that recycling of glutamine not utilized in the kidney for ammonia formation might result in a surplus of glutamine for hepatic synthesis of urea and uric acid, the latter thus contributing to the hyperuricemia of primary gout. In this respect a roughly reciprocal relationship between the urinary excretion of ammonium and that of uric acid is postulated, like the reciprocal relationship between the urinary excretion of ammonium and that of urea, for preservation of nitrogen balance, but on a much smaller scale. The dependence of these relationships upon urine $\mathrm{pH}$ would imply that alkalinization of the urine should result in perceptibly higher blood levels of urea and uric acid. We have not been able to demonstrate unequivocal hyperuricemia resulting from alkalinization of the urine by administration of sodium bicarbonate, but have noted some increase in urinary elimination of uric acid under these circumstances $(26,27)$. When this was first reported it was ascribed, rightly or wrongly, to diminished back-diffusion of urate in alkalinized urine.

The nature of the presumptive renal defect in ammonia production has not been established. It was previously suggested $(1,2)$ that there may be an innate deficiency in renal glutaminase $I$, but we have not yet tested this hypothesis directly, and in view of the complexities of the relationship of the renal glutaminases to production of ammonia by the kidney, further speculations on this point seem fruitless.

\section{Summary}

The urinary elimination of ammonium and titratable acid of 97 gouty subjects, selected for study because they seemed to be free of kidney damage so far as could be determined, was compared in the fasting, postabsorptive state with that of 46 nongouty control subjects excreting urine of the same (acid) $\mathrm{pH}$. There was much dispersion and overlap in the results, but in the 83 gouty subjects who excreted urine of $\mathrm{pH}<$ 4.8 to 5.7 the mean urinary ammonium excretion was significantly less than that of their normal counterparts. The titratable acid was not significantly different in the two groups. There was therefore a mean net deficit in.elimination of metabolic acid, approximating $8 \mu \mathrm{Eq}$ per minute. There was no significant difference between the two groups in subjects whose urine $\mathrm{pH}$ exceeded 5.6.

In 24-hour collections of urine, of acid $\mathrm{pH}$, the mean deficit in ammonium excretion of 18 gouty subjects, as compared to 6 normouricemic nongouty subjects, was $5.5 \mathrm{mEq}$ per day, but there was a mean excess in titratable acid of $7.7 \mathrm{mEq}$ per day; hence there was no significant difference in metabolic acid excretion. After administration of ammonium chloride, the urinary elimination of ammonium and titratable acid increased in the gouty subjects, but significantly less than in the nongouty, to yield a mean peak deficit in metabolic acid excretion of $16.2 \mathrm{mEq}$ per day.

There thus appears to be some selective impairment in renal production of ammonia in many pa- 
tients with primary gout. In the present series of cases this deficiency could not be correlated with other manifestations of overt renal insufficiency, age of the patient, duration of manifest gout, or presence or absence of uric acid urolithiasis. It is therefore believed to be indigenous to primary gout. Contributory insidious and imperceptible kidney damage could not be wholly excluded, however, and may well play a role of variable importance in the gouty population at large.

The deficiency in urinary elimination of ammonium in primary gout presumably contributes to the distinct acidity of the urine, and hence to the strikingly high incidence of uric acid urolithiasis, even in patients not excreting uric acid in excess. It may also be a factor in the overproduction of uric acid characteristic of the disorder.

\section{References}

1. Gutman, A. B., and T. F. Yü. On the nature of the inborn metabolic error (s) of primary gout. Trans. Ass. Amer. Phycns 1963, 76, 141.

2. Gutman, A. B., and T. F. Yü. An abnormality of glutamine metabolism in primary gout. Amer. J. Med. 1963, 35, 820.

3. Pitts, R. F. Renal production and excretion of ammonia. Amer. J. Med. 1964, 36, 720.

4. Sprinson, D. B., and D. Rittenberg. The rate of utilization of ammonia for protein synthesis. J. biol. Chem. 1949, 180, 707.

5. Wu, H. Relative concentration of $\mathrm{N}^{15}$ in urinary ammonia $\mathrm{N}$ and urea $\mathrm{N}$ after feeding $\mathrm{N}^{15}$-labeled compounds. J. gen. Physiol. 1951, 34, 403.

6. Wrong, O., and H. E. F. Davies. The excretion of acid in renal disease. Quart. J. Med. 1959, 28, 259.

7. Van Slyke, D. D., and G. E. Cullen. The mode of action of urease and of enzymes in general. J. biol. Chem. 1914, 19, 141.

8. Bonsnes, R. W., and H. H. Taussky. On the colorimetric determination of creatinine by the Jaffé reaction. J. biol. Chem. 1945, 158, 581.

9. Prætorius, E., and H. Poulsen. Enzymatic determination of uric acid, with detailed directions. Scand. J. clin. Lab. Invest. 1953, 5, 273.

10. Gutman, A. B. Urate urolithiasis in primary and secondary gout. Ann. intern. Med. 1963, 58, 741.

11. Boyce, W. H., F. K. Garvey, and H. E. Strawcutter. Incidence of urinary calculi among patients in general hospitals, 1948 to 1952 . J. Amer. med. Ass. 1956, 161, 1437.
12. Berliner, R. W. Outline of renal physiology in Diseases of the Kidney, M. B. Strauss and L. G. Welt, Eds. Boston, Little, Brown, 1963, p. 66.

13. Van Slyke, D. D., G. C. Linder, A. Hiller, L. Leiter, and J. F. McIntosh. The excretion of ammonia and titratable acid in nephritis. $\mathrm{J}$. clin. Invest. 1926, 2, 255.

14. Schwartz, W. B., P. W. Hall, 3rd, R. M. Hays, and A. S. Relman. On the mechanism of acidosis in chronic renal disease. J. clin. Invest. 1959, 38, 39.

15. Briggs, A. P., T. Findley, and W. S. Harms. Further observations on the renal production of acid in uremia. Metabolism 1964, 13, 107.

16. Barzel, U. S., O. Sperling, M. Frank, and A. DeVries. Renal ammonium excretion and urinary $\mathrm{pH}$ in idiopathic uric acid lithiasis. J. Urol. (Baltimore) 1964, 92, 1.

17. Steinmetz, P. R., R. P. Eisinger, and J. Lowenstein. The excretion of acid in unilateral renal disease in man. J. clin. Invest. 1965, 44, 582.

18. McCance, R. A., W. J. Matheson, G. A. Gresham, and J. R. Elkinton. The cerebro-ocular-renal dystrophies: a new variant. Arch. Dis. Childh. 1960, $35,240$.

19. Elkinton, J. R., E. J. Huth, G. D. Webster, Jr., and R. A. McCance. The renal excretion of hydrogen ion in renal tubular acidosis. I. Quantitative assessment of the response to ammonium chloride as an acid load. Amer. J. Med. 1960, 29, 554.

20. Henneman, P. H., S. Wallach, and E. F. Dempsey. The metabolic defect responsible for uric acid stone formation. J. clin. Invest. 1962, 41, 537.

21. Woeber, K. A., L. Ricca, and A. G. Hills. Pathogenesis of uric acid urolithiasis. Clin. Res. 1962, $10,45$.

22. Gutman, A. B., and T. F. Yü. Renal function in gout, with a commentary on the renal regulation of urate excretion, and the role of the kidney in the pathogenesis of gout. Amer. J. Med. 1957, 23, 600.

23. Yü, T. F., L. Berger, and A. B. Gutman. Renal function in gout. II. Effect of uric acid loading on renal excretion of uric acid. Amer. J. Med. 1962, 33, 829.

24. Gutman, A. B. Significance of the renal clearance of uric acid in normal and gouty man. Amer. $\mathrm{J}$. Med. 1964, 37, 833.

25. Clarke, E., B. M. Evans, I. MacIntyre, and M. D. Milne. Acidosis in experimental electrolyte depletion. Clin. Sci. 1955, 14, 421.

26. Gutman, A. B., T. F. Yü, and J. H. Sirota. Contrasting effects of bicarbonate and Diamox, with equivalent alkalinization of urine, on salicylate uricosuria in man. Fed. Proc. 1956, 15, 85.

27. Gutman, A. B., and T. F. Yü. A three-component system for regulation of renal excretion of uric acid in man. Trans. Ass. Amer. Phycns 1961, 74, 353. 